\title{
Antibiofilm efficacy of tea tree oil and of its main component terpinen-4-ol against Candida albicans
}

\author{
Renata Serignoli \\ FRANCISCONI(a) \\ Patricia Milagros Maquera \\ $\mathrm{HUACHO}^{(a)}$ iD \\ Caroline Coradi TONON(a) \\ Ester Alves Ferreira BORDINI(a) \\ Marília Ferreira CORREIA(a) iD \\ Janaína de Cássia Orlandi \\ SARDI (b) \\ Denise Madalena Palomari \\ SPOLIDORIO(a) iD \\ (a) Universidade Estadual Paulista - Unesp, \\ School of Dentistry of Araraquara, \\ Department of Physiology and Pathology, \\ Araraquara, SP, Brazil \\ (b) Universidade Estadual de Campinas - \\ Unicamp, School of Dentistry of Piracicaba, \\ Department of Physiological Sciences, \\ Piracicaba, SP, Brazil.
}

Declaration of Interests: The authors certify that they have no commercial or associative interest that represents a conflict of interest in connection with the manuscript.

Corresponding Author:

Denise M. Palomari Spolidorio

E-mail: despolidorio@gmail.com

https://doi.org/10.1590/1807-3107bor-2020.vol34.0050

Submitted: October 29, 2019

Accepted for publication: March 30, 2020

Last revision: April 28, 2020

\begin{abstract}
Candida infection is an important cause of morbidity and mortality in immunocompromised patients. The increase in its incidence has been associated with resistance to antimicrobial therapy and biofilm formation. The aim of this study was to evaluate the efficacy of tea tree oil (TTO) and its main component - terpinen-4-ol against resistant Candida albicans strains (genotypes A and B) identified by molecular typing and against C. albicans ATCC 90028 and SC 5314 reference strains in planktonic and biofilm cultures. The minimum inhibitory concentration, minimum fungicidal concentration, and rate of biofilm development were used to evaluate antifungal activity. Results were obtained from analysis of the biofilm using the cell proliferation assay 2,3-Bis-(2-methoxy-4-nitro-5-sulfophenyl)-2Htetrazolium-5-carboxanilide (XTT) and confocal laser scanning microscopy (CLSM). Terpinen-4-ol and TTO inhibited C. albicans growth. CLSM confirmed that $17.92 \mathrm{mg} / \mathrm{mL}$ of TTO and $8.86 \mathrm{mg} / \mathrm{mL}$ of terpinen-4-ol applied for $60 \mathrm{~s}$ (rinse simulation) interfered with biofilm formation. Hence, this in vitro study revealed that natural substances such as TTO and terpinen-4-ol present promising results for the treatment of oral candidiasis.
\end{abstract}

Keywords: Biofilms; Candida albicans; Mycoses; Phytotherapy.

\section{Introduction}

Candida albicans is among the most prevalent fungal species of the human microbiota. It is also an opportunistic pathogen that can cause severe, and often fatal, bloodstream infections. ${ }^{1}$ However, among its different virulence factors, the initial adhesion, with biofilm formation on abiotic and biotic surfaces, plays a critical role in pathogenesis. ${ }^{2}$ Drug resistance is becoming increasingly concerning, and the search for new agents may lead to the development of new antifungal agents that are effective against biofilms. Traditional medicinal plants and alternative therapies have been attractive sources for identifying new antimicrobial agents. ${ }^{3}$

Natural products are considered an important source for the development of new antifungal therapies. Several studies have shown antimicrobial activity of these products on oral pathogens, showing that these herbal agents can be vehicles for prevention and control of infectious oral 
diseases. ${ }^{4}{ }^{5}$ Melaleuca alternifolia, of the botanical family Myrtaceae, is a plant native to Australia also known as tea tree. The steam distillation of its leaves produces an oil known as tea tree oil (TTO). TTO is a mixture of approximately 100 compounds, including terpinen-4-ol (at least $30 \%$ of the oil), 1,8-cineole, and terpinolene. ${ }^{5}$ TTO demonstrates a broad spectrum of biological activities, including a wide variety of microorganisms that can be used to improve strategies for the treatment of chronic infections such as candidiasis, pharyngitis, vaginitis, and respiratory tract diseases. TTO acts within biological membranes, damaging their integrity and inhibiting the action of enzymes incorporated to increase membrane fluidity, with subsequent leakage of intracellular components. ${ }^{6}$ According to Cox and Markham, ${ }^{6}$ chemical constituents are characteristically hydrophobic and will accumulate in the lipid-rich environments of cell membrane structures and cause structural and functional damage.

The International Standard Organization ${ }^{7}$ regulates the concentration ranges of the major TTO terpenes and related alcohols and ethers, including directives on the levels of these components: the minimum content of terpinen-4-ol should be at least $30 \%$ and the maximum content of 1,8-cineole should be less than $15 \%$ of the oil volume. Terpinen-4-ol is the main active compound within TTO and has gained attention because of its antimicrobial, antifungal, and anti-inflammatory properties. ${ }^{8}$ Terpinen-4-ol is known to induce membrane loss, disrupting the integrity and physiology of microbial cells. Low concentrations of terpinen-4-ol are not toxic to fibroblasts and epithelial cells, allowing for topical use with reduced adverse effects. ${ }^{9,10,11,12}$

The aim of this study was to evaluate the efficacy of TTO and of its main component - terpinen-4-ol against resistant clinical isolates of Candida albicans strains and C. albicans ATCC 90028 and SC 5314 reference strains in planktonic and biofilm cultures.

\section{Methodology}

\section{Melaleuca alternifolia Cheel (tea tree) oil and its components}

TTO composition was analyzed by gas chromatography in compliance with ISO $4730 .{ }^{7}$ To prepare the samples, $1 \mu \mathrm{L}$ of TTO was dissolved in $1 \mu \mathrm{L}$ of ethanol and injected into an HP35 capillary column with carrier gas at a flow rate of $0.8 \mathrm{~mL} / \mathrm{min}$. The temperature of the injector and detector was $250^{\circ} \mathrm{C}$. The temperature regimen was as follows: initial temperature of $80^{\circ} \mathrm{C}$ for $2 \mathrm{~min}$, increase by $10^{\circ} \mathrm{C} / \mathrm{min}$ to $250^{\circ} \mathrm{C}$, and constant temperature for the final $10 \mathrm{~min} \cdot{ }^{13}$ The concentrations were determined at the time of fractionation. Gas chromatography showed TTO complied with ISO 4730:2017 ${ }^{7}$ and the relative concentrations of the components showed terpinen-4-ol was present in $47.66 \%$. Terpinen-4-ol was purchased from Sigma-Aldrich.

\section{Tea tree oil and terpinen-4-ol: stock solutions}

The following stock solutions of TTO were prepared: TTO $2.24 \mathrm{mg} / \mathrm{mL}-17.92 \mathrm{mg} / \mathrm{mL}$ and terpinen-4-ol 1.02 $\mathrm{mg} / \mathrm{mL}-8.86 \mathrm{mg} / \mathrm{mL}$ (Sigma-Aldrich, St. Louis, MO, USA) were diluted in Roswell Park Memorial Institute (RPMI 1640) culture medium (Sigma-Aldrich) at $\mathrm{pH}$ 7.0 with $0.165 \mathrm{M}$ of $3-(\mathrm{N}$-morpholino) propanesulfonic acid (MOPS) and $0.4 \%$ of dimethyl sulfoxide (DMSO) as a solubilizing agent. ${ }^{8}$ The standard powder used to prepare nystatin was dissolved in DMSO. The nystatin stock solution $(500 \mu \mathrm{g} / \mathrm{mL})$ was kept at $-70^{\circ} \mathrm{C}$ until use.

\section{Candida albicans strains}

This study included two C. albicans clinical strains previously identified by molecular typing as genotypes $\mathrm{A}$ and $\mathrm{B}$, isolated from diabetic patients with chronic periodontitis (Ethics Committee process no. 062/2008). ${ }^{14}$ C. albicans ATCC 90028 and SC 5314 reference strains were also used.

\section{Preparation of the initial Candida albicans suspension}

Prior to each experiment, the yeast strains were cultured in RPMI at $37^{\circ} \mathrm{C}$ for $18 \mathrm{~h}$. After incubation, the cells were harvested, washed with phosphate-buffered saline (PBS) at pH 7.2, and resuspended in RPMI. All C. albicans suspensions $\left(10^{7} \mathrm{CFU} \mathrm{mL} \mathrm{mL}^{-1}\right)$ were prepared by adjusting the optical density (OD) at 600 nm (Multiskan Ascent 354, EC Labsystems, Les Ulis, France). 


\section{Determination of minimum inhibitory concentration and minimum fungicidal concentration values for TTO and terpinen-4-ol}

The activity of TTO and terpinen-4-ol against the $C$. albicans strains tested was determined by the broth microdilution method (M27-A, 2008). ${ }^{15}$ TTO and terpinen-4-ol were serially diluted in RPMI 1640 with $0.4 \%$ DMSO. The same volume of the $C$. albicans suspension was added to each well to obtain a final density of $1.0 \times 10^{3} \mathrm{CFU} \mathrm{mL} \mathrm{m}^{-1}$. RPMI medium with DMSO and C. albicans and nystatin (without TTO and terpinen-4-ol) were used as control groups. After 24 $\mathrm{h}$ of incubation at $37^{\circ} \mathrm{C}$, cell growth was assessed visually and by absorbance at $590 \mathrm{~nm}$.

The MIC was defined as the lowest concentration of TTO and terpinen-4-ol that led to no visible growth of the cell strains tested. The MFC value was defined as the lowest concentration of TTO and terpinen-4-ol that showed no growth of $C$. albicans colonies. To determine the MFC, the samples were seeded onto Sabouraud dextrose agar (SDA) plates and maintained thereon at $37^{\circ} \mathrm{C}$ for $48 \mathrm{~h}$. All assays were performed in triplicate as independent experiments.

\section{Metabolic activity of Candida albicans biofilm}

XTT (2,3-bis(2-methoxy-4-nitro-5-sulfophenyl)-2Htetrazolium-5-carboxanilide) (Sigma) assay was used to determine the metabolic activity of the biofilm. ${ }^{16}$ Biofilms were allowed to form on microtiter plates and after $24 \mathrm{~h}$ of exposure to TTO, terpinen-4-ol, and nystatin. The solutions and non-adherent cells were removed by washing twice with sterile PBS. The biofilms were then treated with $158 \mu \mathrm{L}$ of PBS containing $200 \mathrm{mM}$ of glucose, $40 \mu \mathrm{L}$ of XTT, and $2 \mu \mathrm{L}$ of diluted menadione. After incubation with the XTT solution, absorbance was recorded at $490 \mathrm{~nm}$.

\section{Biofilm growth inhibition}

Biofilm was allowed to grow in microtiter plates. ${ }^{8}$ The biofilms were treated with a range of different concentrations of TTO, terpinen-4-ol, and RPMI 1640 containing 0.4\% DMSO (control group). C. albicans biofilms were prepared by adding 100 $\mu \mathrm{L}$ of the isolated suspension containing $1 \times 10^{5} \mathrm{CFU}$ $\mathrm{mL}^{-1}$ into the wells, which were kept at $37^{\circ} \mathrm{C}$ for 1.5 h. Thereafter, the cell suspension was replaced with $100 \mu \mathrm{L}$ of RPMI 1640 medium and the plates were incubated at $37^{\circ} \mathrm{C}$ for $24 \mathrm{~h}$ in a shaker at $75 \mathrm{rpm}$. Metabolic activity was quantified by the XTT assay after $48 \mathrm{~h}$ of incubation. ${ }^{16}$ All experiments were performed on three independent occasions.

\section{Biofilm formation on denture base resin specimens and mouthwash simulation}

Denture base acrylic resin was chosen for this study (Vipi Colorless Wave). The final dimensions of the disc-shaped acrylic resin patterns were $10 \mathrm{~mm}$ in diameter and $2 \mathrm{~mm}$ in thickness. The surface roughness of specimens was measured $(0.2 \mu \mathrm{m})$ (Mitutoyo Surftest SJ-401, Mitutoyo Corporation, Japan). Distribution between experimental and control groups was determined by randomization and restriction. Prior to the experiment, the specimens were sterilized with ethylene oxide.

The assays for adhesion and biofilm formation were performed according to the literature. ${ }^{17}$ Each denture base acrylic resin specimen was placed in sterile 24-well flat-bottomed microtiter plates. Then, $1 \mathrm{~mL}$ of human saliva was added, incubated for $1 \mathrm{~h}$ at $37^{\circ} \mathrm{C}$, and shaken at $75 \mathrm{rpm}$ to allow salivary pellicle formation on the specimens. ${ }^{18}$ Human unstimulated whole saliva (Certificate of Presentation for Ethical Consideration - CAAE 06687412.5.0000.5416) was collected and clarified by centrifugation at $3,800 \mathrm{~g}$ for $10 \mathrm{~min}$ at $4^{\circ} \mathrm{C}$. The supernatant was sterilized by filtration $(22 \mu \mathrm{m})$ and stored at $-70^{\circ} \mathrm{C}$ until use.

After incubation, C. albicans was dispensed into each well and the plates were incubated at $37^{\circ} \mathrm{C}$ for $90 \mathrm{~min}$ (adhesion assay) at $75 \mathrm{rpm}$ and for $72 \mathrm{~h}$. The culture medium was renewed every $24 \mathrm{~h}$ during biofilm formation. After biofilm formation, each specimen was treated with $1 \mathrm{~mL}$ of the solutions for $60 \mathrm{~s}$, simulating the clinical application of mouthwash: $17.92 \mathrm{mg} / \mathrm{mL}$ of TTO, $8.86 \mathrm{mg} / \mathrm{mL}$ of terpinen-4-ol, $256 \mu \mathrm{g} / \mathrm{mL}$ of nystatin and phosphate-buffered saline. Subsequently, residual biofilms were disrupted and adhered microorganisms were removed from the specimens by sonication ( $7 \mathrm{~W}$ for $20 \mathrm{~s})^{19}$ and then washed with PBS. The cell viability of the biofilm was evaluated by XTT assay and by confocal laser scanning microscopy. 


\section{Confocal laser scanning microscopy}

Biofilms formed on the denture base acrylic resin surfaces were stained using the Live/Dead BacLight Viability kit, comprising SYTO-9 (Invitrogen). Images of the stained biofilms were captured using a CLSM system (Leica TCS SPE, Leica Microsystems, Wetzlar, Germany).

\section{Statistical analyses}

Statistical analysis was performed using Statistical Package for the Social Sciences - SPSS version 17.0 (Chicago, USA). All data were analyzed for the presence of outliers, assumptions of normality (Shapiro-Wilk test), and homogeneity of variance (Levene's test). One-way ANOVA, followed by Tukey's test, was also used. The significance level for all statistical tests was set at $5 \%(p<0.05)$.

\section{Results}

\section{Antifungal activity}

The concentrations of TTO, terpinen-4-ol, and nystatin able to inhibit growth (MIC) in planktonic cultures of $C$. albicans clinical strains (A, B) were $8.96 \mathrm{mg} / \mathrm{mL}, 4.53 \mathrm{mg} / \mathrm{mL}$, and $8 \mu \mathrm{g} / \mathrm{mL}$, respectively. Regarding the MFC, lower concentrations were observed for TTO $(17.92 \mathrm{mg} / \mathrm{mL})$, terpinen-4-ol $(8.86 \mathrm{mg} / \mathrm{mL})$, and nystatin $(16 \mu \mathrm{g} / \mathrm{mL})$. In general, the clinical samples from genotypes A and B showed greater resistance. The MIC and MFC values were similar for C. albicans reference strains.

\section{Cell viability assay}

Figure 1 shows the higher effect of $17.92 \mathrm{mg} / \mathrm{mL}$ of TTO and $8.86 \mathrm{mg} / \mathrm{mL}$ of terpinen-4-ol $(\mathrm{p}<0.05)$ on all C. albicans biofilms formed in polystyrene plates. No significant difference was found between $17.92 \mathrm{mg} / \mathrm{mL}$ of TTO and nystatin on C. albicans biofilms A and B. Thus, we considered that $8.86 \mathrm{mg} / \mathrm{mL}$ of terpinen-4-ol had a significantly higher effect against cell viability of all isolates.

Figure 2 shows the XTT results expressed by OD at $492 \mathrm{~nm}$, where $17.92 \mathrm{mg} / \mathrm{mL}$ of TTO and $8.86 \mathrm{mg} / \mathrm{mL}$ of terpinen-4-ol were effective against the biofilm formed on the specimens when compared to the control for all strains tested, excepted for strain A, where TTO and terpinen-4-ol were not statistically different from all groups $(\mathrm{p}<0.05)$.

\section{Confocal laser scanning microscopy on acrylic resin specimens}

A confocal microscope was used to examine images of the biofilm species in terms of structure and interactions between $C$. albicans biofilms exposed to TTO and to terpinen-4-ol, which grew on the denture base acrylic resin specimens (Figure 3).

Representative CLSM images of the control group (A1, B1, C1, D1) showed a contiguous layer of cells of $C$. albicans, which initially presented formation of hyphae and then evolved into a mature biofilm, producing a thick layer of co-aggregated cells with a homogeneous mass of viable microorganisms and some dead cells.

The activity of nystatin, TTO, and terpinen4-ol showed a non-contiguous layer of cells, with preferential association to the hyphal elements of $C$. albicans and, to a lesser extent, round yeast cells and reddish yellow coloration, which means non-viable cells. Furthermore, in most samples, the biofilm presented adhesion with a lower quantity of uniformly distributed cells.

The results from antimicrobial activity assessments and analysis of the CLSM images showed that TTO, terpinen-4-ol, and nystatin obtained similar results, except for genotype $\mathrm{A}$, which was the most resistant to the action of the test components and nystatin (C1-C4).

\section{Discussion}

TTO and its components are the most commonly used essential oil because of their antibacterial and antifungal properties. ${ }^{8,12,20}$ In this study, we evaluated the efficacy of TTO and its main bioactive component - terpinen-4-ol - against C. albicans clinical strains (genotypes A and B), and ATCC 90028 and SC 5314 C. albicans reference strains in planktonic and biofilm cultures.

The ability of $C$. albicans to adhere and form biofilm is essential to the development of candidiasis. The antifungal activity of TTO and terpinen-4-ol was able to control biofilm proliferation in vitro. MIC and MFC results proved to be highly active against 


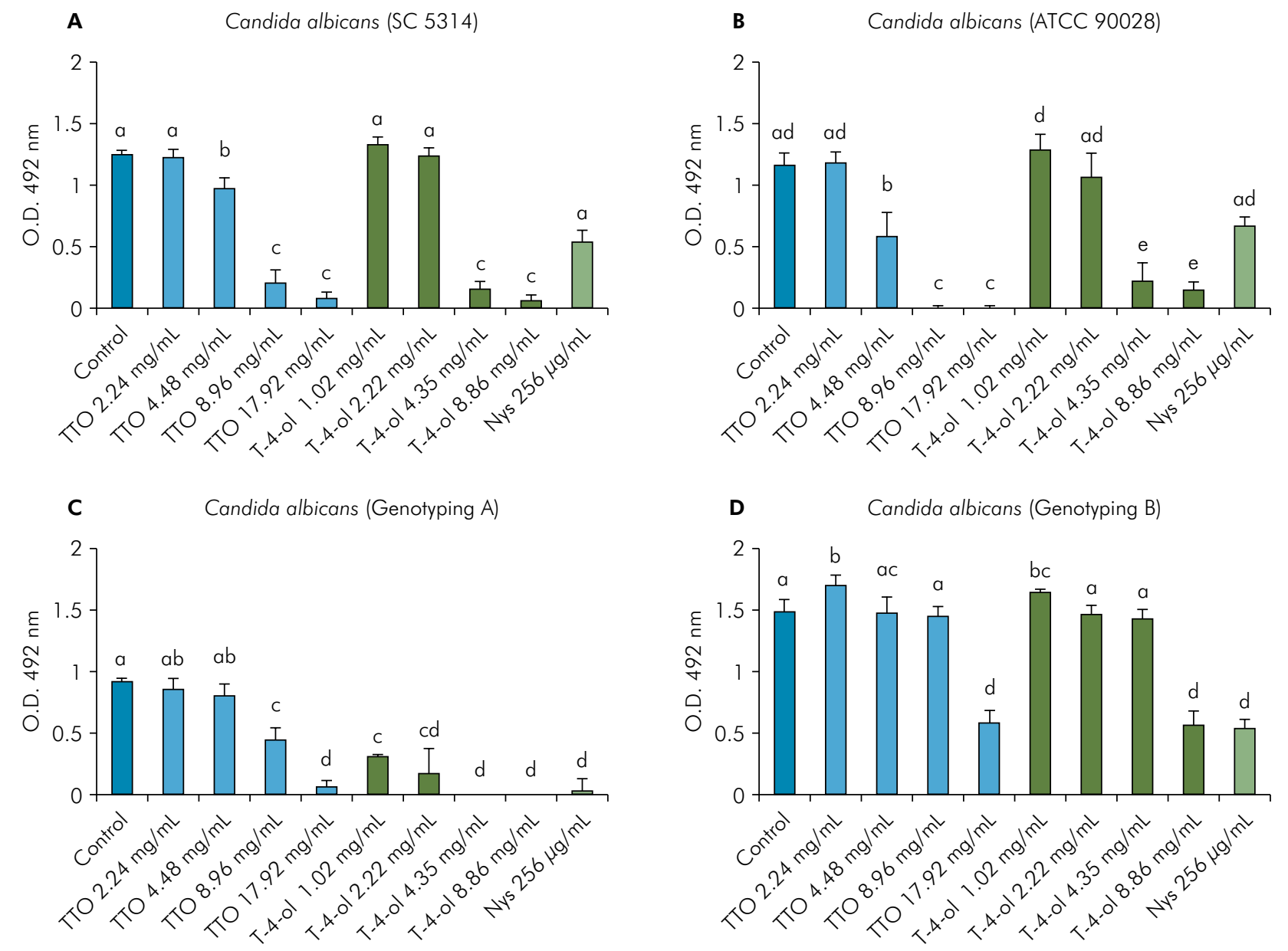

Figure 1. Analysis of cell viability (XTT) of TTO, terpinen-4-ol, and nystatin on biofilm of Candida albicans SC 5314 (A), ATCC 90028 (B), Genotyping A (C), Genotyping B (D), formed in polystyrene (sterile 96-well flat-bottomed microtiter plates). Statistical differences are indicated by different letters.

planktonic cells of C. albicans, corroborating the findings of previous studies. ${ }^{9,20,21,22}$ Mondello et al. ${ }^{23}$ found that terpinen-4-ol was as effective as TTO in accelerating vaginal clearance of all the examined Candida-resistant strains. The present study also showed that terpinen-4-ol has been investigated as an antifungal in resistant $C$. albicans strains, since resistance to antimicrobial drugs is the major obstacle to the treatment of candidiasis. In this study, the increasing concentrations of TTO and terpinen-4-ol were significantly able to eliminate biofilm from ATCC 90028 and SC 5314 reference strains. However, the activity of TTO and terpinen-4-ol was lower on the biofilms of C. albicans strains (genotypes A and B), but not effective enough to eliminate $C$. albicans strains completely. This could be occurring because the strains isolated from diabetic patients might have been subjected to antifungal activity and become highly prone to environmental stress. However, both compounds showed a lower effect on the eradication of C. albicans (genotype B) biofilm when compared to the control group (nystatin) (Figure 1). The highest concentrations could be explained by the fact that the biofilm becomes more resistant than in planktonic culture because of intraspecies and interspecies metabolic changes. ${ }^{19}$ The effectiveness of TTO and its main component has been observed previously. ${ }^{9}$

Nystatin binds to steroids within the cell membranes of susceptible fungi, disrupting the permeability of the cell membrane and causing the cytoplasmic content to leak from the cell; however, it has several side effects in humans, including 

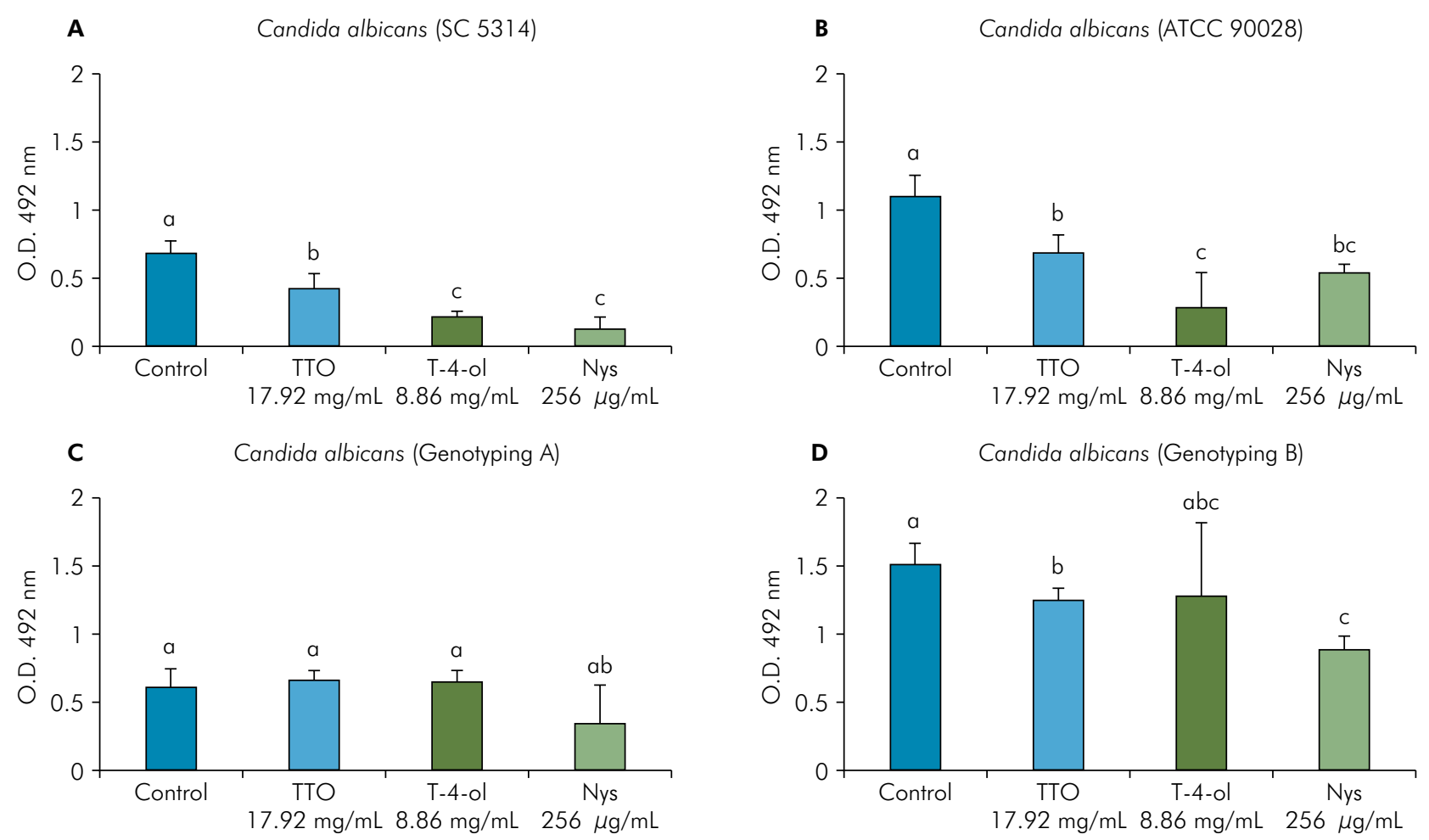

Figure 2. Analysis of cell viability (XTT) of TTO, terpinen-4-ol, and nystatin on biofilm of Candida albicans SC 5314 (A), ATCC 90028 (B), Genotyping A (C), Genotyping B (D), grown on denture base resin specimens. Statistical differences are indicated by different letters.
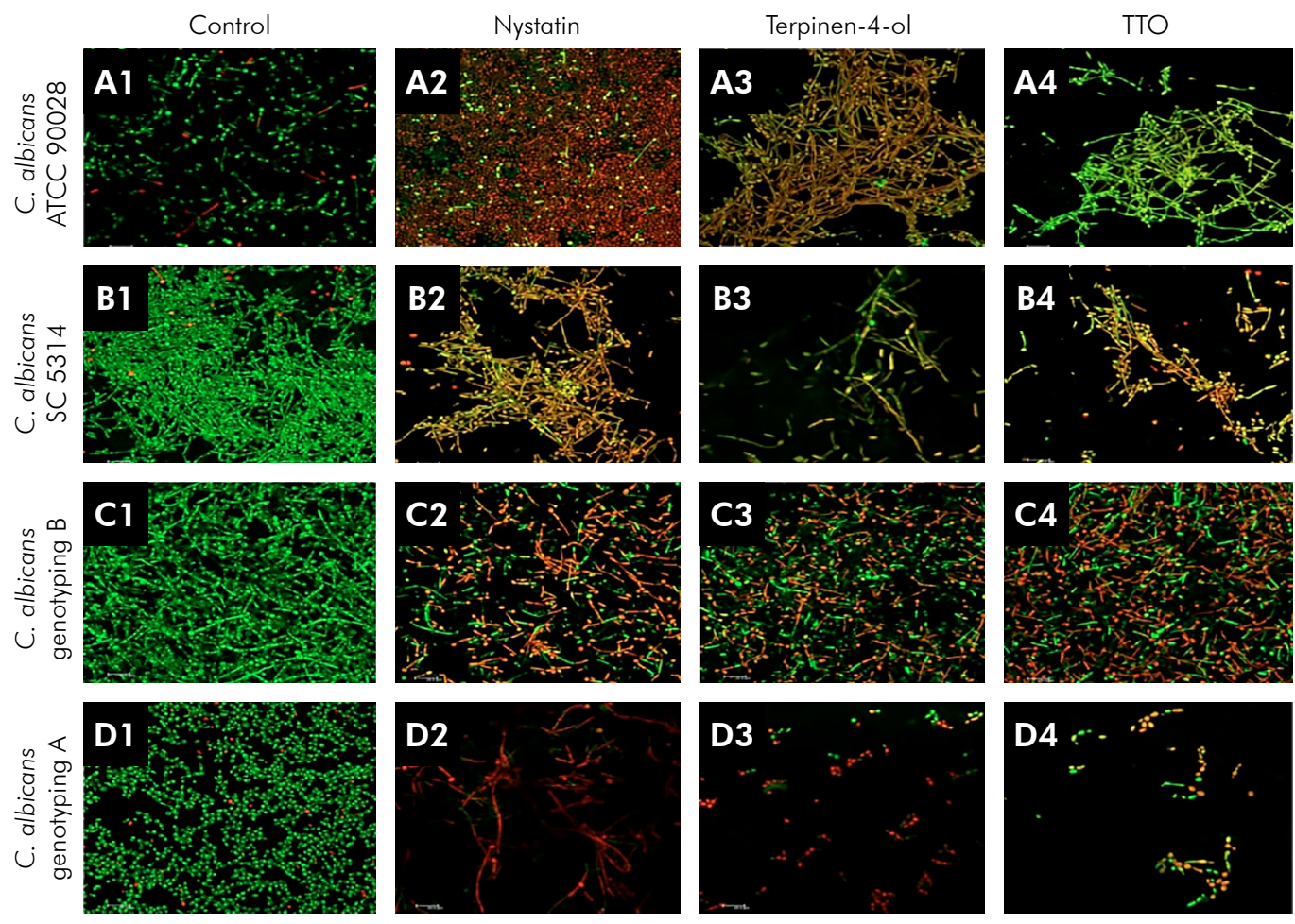

Figure 3. Representative CLSM images of Candida albicans ATCC 90028 (A), SC 5314 (B) genotyping A (C), and genotyping B (D) biofilms formed on the specimens and exposed to PBS (control group) (1), nystatin (2), terpinen-4-ol (3), and TTO (4). 
gastrointestinal disorders and an unpleasant taste. ${ }^{24}$ The topical use of nystatin is limited in terms of the period of localization, mainly as a result of the addition of flavoring agents, which increase the volume of saliva in the region, thus reducing its residence time at the injured site, hindering the effectiveness of treatment. ${ }^{25,26}$ By contrast, terpinen-4-ol disrupts the fungal cell membrane and interferes with the pathogen's cell integrity and physiology. The present results are in line with those of Ramage et al. ${ }^{9}$ and Tonon et al. ${ }^{27}$ who showed strong antimicrobial properties of terpinen-4-ol against planktonic cultures and fungal biofilms, indicating that it may be suitable for the prophylaxis and treatment of candidiasis.

Studies demonstrated that TTO decreases biofilm formation and attachment of different $C$. albicans strains to biotic and abiotic surfaces. However, TTO has some problems associated with its physical properties, such as low water miscibility and high volatilization rates, resulting in low stability. ${ }^{28,29}$

Biofilms demonstrate wettability (ability of a liquid to maintain contact with a solid surface), as a result of the great number of intermolecular interactions. This explains some factors that affect the penetration of antifungal agents into different cell walls and into the polymeric matrix of the biofilm. . $^{30,31}$

Candida species are microorganisms that live commensally in the oral cavity of healthy individuals, but their incidence and virulence seem to be increased in those who are immunocompromised. This explains why $C$. albicans clinical strains previously identified as genotypes $\mathrm{A}$ and $\mathrm{B}$, isolated from diabetic patients with chronic periodontitis, present physiological changes in the host, causing oral candidiasis or invasive systemic infections. This growing trend has been associated with resistance to the antimicrobial therapy and with the ability of the microorganism to form biofilms. The increasing microbial resistance rates may also result from longterm drug exposure or from the selection of strains with intrinsic resistance mechanisms. ${ }^{14}$

Another property of Candida spp. is their ability to grow either aerobically or anaerobically as they have developed adaptive mechanisms to survive in both situations. Oxygen can generate reactive products during an infection and induce an oxidative stress response. Treatment of $C$. albicans with low concentrations of superoxide-generating agents, such as hydrogen peroxide, induces a redox potential with the activation of antioxidant enzymes, protecting cells from the lethal effects of a subsequent challenge with higher concentrations of these oxidants. Another problem is posed by anaerobic environments, such as root canal systems and periodontal pockets, which lead to polymicrobial infections. ${ }^{32}$

This study also assessed biofilm viability in acrylic resin specimens. Denture materials themselves can contribute to denture stomatitis, as the roughness and hydrophobicity of denture surfaces can promote microbial adhesion and biofilm formation. Surface roughness was also evaluated. It has been reported that surface roughness is the main factor that affects microbial adhesion and biofilm formation on denture base surfaces. ${ }^{17}$ Therefore, we measured the surface roughness of each specimen to avoid the effect of an irregular surface on C. albicans adhesion and biofilm formation. An essential event in the onset of denture stomatitis is the adhesion of $C$. albicans to the denture base. After adhesion occurs, mature biofilm forms on the surface of dentures, resulting in denture stomatitis in the presence of a suitable environment. Therefore, controlling C. albicans adhesion and biofilm formation on the denture base is vital for preventing denture stomatitis. ${ }^{33}$

The results show that the images obtained by CLSM confirmed that $17.92 \mathrm{mg} / \mathrm{mL}$ of TTO and $8.86 \mathrm{mg} / \mathrm{mL}$ of terpinen-4-ol applied for $60 \mathrm{~s}$ (rinse simulation) are effective and comparable to treatment with nystatin and interfere with biofilm formation. These results were confirmed by the XTT assay and our in vitro data confirm that TTO and terpinen-4-ol have the same antimicrobial activity. Results showing a preventive effect were observed using $2.24 \mathrm{mg} / \mathrm{mL}$ of TTO to inhibit biofilm formation on various $C$. albicans samples. ${ }^{28}$ Under these conditions, low concentrations of TTO can be used to prevent infection and to treat existing fungal infections. ${ }^{20}$

The results of the present study indicate that TTO and terpinen-4-ol have antifungal activity against Candida strains. The mechanism of action of TTO on cells has not been elucidated, but it is believed to 
have a lipophilic character as TTO interacts with the cell membrane and then disrupts its normal activity. ${ }^{11}$

In summary, studies suggest that TTO penetrates through the cell wall and cytoplasmic membrane of fungal strains, causing damage to these structures, with subsequent loss of cytoplasmic material. Essential oils can penetrate the cytoplasmic membrane because of their lipophilicity. ${ }^{22,34} \mathrm{Li}$ et al. ${ }^{22}$ showed that TTO and terpinen-4-ol might penetrate fungal organelle membranes and induce organelle damage. Finally, these irreversible TTO-mediated changes lead to cell death and showed antifungal activities against $C$. albicans strains. This activity was mainly attributed to the presence of terpinen-4-ol, which showed equivalent antimicrobial activity against these fungal strains.

\section{Conclusions}

The experimental data strengthen the contribution of TTO and terpinen-4-ol activity in vitro, suggesting that they can be used for both prevention and treatment of fungal infections.

\section{Acknowledgment}

This study was supported by the São Paulo Research Foundation - Brazil - Fapesp (process no. 2012/15680-4).

\section{References}

1. Lohse MB, Gulati M, Johnson AD, Nobile CJ. Development and regulation of single- and multi-species Candida albicans biofilms. Nat Rev Microbiol. 2018 Jan;16(1):19-31. https://doi.org/10.1038/nrmicro.2017.107

2. Figueiral MH, Azul A, Pinto E, Fonseca PA, Branco FM, Scully C. Denture-related stomatitis: identification of aetiological and predisposing factors - a large cohort. J Oral Rehabil. 2007 Jun;34(6):448-55. https://doi.org/10.1111/j.1365-2842.2007.01709.x

3. Grando TH, Sá MF, Baldissera MD, Oliveira CB, Souza ME, Raffin RP, et al. In vitro activity of essential oils of free and nanostructured Melaleuca alternifolia and of terpinen-4-ol on eggs and larvae of Haemonchus contortus. J Helminthol. 2016 May;90(3):377-82. https://doi.org/10.1017/S0022149X15000401

4. Catalán A, Pacheco JG, Martínez A, Mondaca MA. In vitro and in vivo activity of Melaleuca alternifolia mixed with tissue conditioner on Candida albicans. Oral Surg Oral Med Oral Pathol Oral Radiol Endod. 2008 Mar;105(3):327-32. https://doi.org/10.1016/i.tripleo.2007.08.025

5. Hammer KA, Dry L, Johnson M, Michalak EM, Carson CF, Riley TV. Susceptibility of oral bacteria to Melaleuca alternifolia (tea tree) oil in vitro. Oral Microbiol Immunol. 2003 Dec;18(6):389-92. https://doi.org/10.1046/i.0902-0055.2003.00105.x

6. Cox SD, Markham JL. Susceptibility and intrinsic tolerance of Pseudomonas aeruginosa to selected plant volatile compounds. J Appl Microbiol. 2007 Oct;103(4):930-6. https://doi.org/10.1111/j.1365-2672.2007.03353.x

7. International Organization for Standardization - ISO. ISO 4730:2017: Essential oil of Melaleuca, terpinen-4-ol type (Tea Tree oil). Geneva: International Organization for Standardization; 2017.

8. Francisconi RS, Bordini EA, Nogueira MN, et al. Effect of Melaleuca alternifolia and its components on Candida albicans and C. tropicalis. J US-China Med Sci. 2015;12:91-8. https://doi.org/10.17265/1548-6648/2015.03.001

9. Ramage G, Milligan S, Lappin DF, Sherry L, Sweeney P, Williams C, et al. Antifungal, cytotoxic, and immunomodulatory properties of tea tree oil and its derivative components: potential role in management of oral candidosis in cancer patients. Front Microbiol. 2012 Jun;3:220-40. https://doi.org/10.3389/fmicb.2012.00220

10. Carson CF, Hammer KA, Riley TV. Melaleuca alternifolia (Tea Tree) oil: a review of antimicrobial and other medicinal properties. Clin Microbiol Rev. 2006 Jan;19(1):50-62. https://doi.org/10.1128/CMR.19.1.50-62.2006

11. Maquera-Huacho PM, Tonon CC, Correia MF, Francisconi RS, Bordini EA, Marcantonio É Jr, et al. In vitro antibacterial and cytotoxic activities of carvacrol and terpinen-4-ol against biofilm formation on titanium implant surfaces. Biofouling. 2018 Jul;34(6):699-709. https://doi.org/10.1080/08927014.2018.1485892

12. Maquera PM, Rodriguez Herrero E, Verspecht T, Pauwels M, Marcantonio Jr E, Palomari Spolidorio DM, et al. Terpinen-4-ol and carvacrol affect multi-species biofilm composition. Biofouling. 2019;35(5):1-12. https://doi.org/10.1080/08927014.2019.1630386

13. Nogueira MN, Aquino SG, Rossa Junior C, Spolidorio DM. Terpinen-4-ol and alpha-terpineol (tea tree oil components) inhibit the production of IL-1 $\beta$, IL-6 and IL-10 on human macrophages. Inflamm Res. 2014 Sep;63(9):769-78. https://doi.org/10.1007/s00011-014-0749-x 
Francisconi RS, Huacho PMM, Tonon CC, Bordini EAF, Correia MF, Sardi JCO, et al.

14. Sardi JC, Duque C, Höfling JF, Gonçalves RB. Genetic and phenotypic evaluation of Candida albicans strains isolated from subgingival biofilm of diabetic patients with chronic periodontitis. Med Mycol. 2012 Jul;50(5):467-75. https://doi.org/10.3109/13693786.2011.633233

15. Clinical Laboratory Standards Institute. Reference method for broth dilution antifungal susceptibility testing of yeast: 2008 approved standard. 3rd Ed. Wayne: Clinical Laboratory Standards Institute; 2008. (CLSI document M27-A3).

16. Jin Y, Yip HK, Samaranayake YH, Yau JY, Samaranayake LP. Biofilm-forming ability of Candida albicans is unlikely to contribute to high levels of oral yeast carriage in cases of human immunodeficiency virus infection. J Clin Microbiol. 2003 Jul;41(7):2961-7. https://doi.org/10.1128/JCM.41.7.2961-2967.2003

17. Wady AF, Machado AL, Zucolotto V, Zamperini CA, Berni E, Vergani CE. Evaluation of Candida albicans adhesion and biofilm formation on a denture base acrylic resin containing silver nanoparticles. J Appl Microbiol. 2012 Jun;112(6):1163-72. https://doi.org/10.1111/j.1365-2672.2012.05293.x

18. Zamperini CA, Machado AL, Vergani CE, Pavarina AC, Giampaolo ET, Cruz NC. Adherence in vitro of Candida albicans to plasma treated acrylic resin. Effect of plasma parameters, surface roughness and salivary pellicle. Arch Oral Biol. 2010 Oct;55(10):763-70. https://doi.org/10.1016/i.archoralbio.2010.06.015

19. Marsh PD. Dental plaque as a microbial biofilm. Caries Res. 2004 May-Jun;38(3):204-11. https://doi.org/10.1159/000077756

20. Hammer KA, Carson CF, Riley TV, Nielsen JB. A review of the toxicity of Melaleuca alternifolia (tea tree) oil. Food Chem Toxicol. 2006 May;44(5):616-25. https://doi.org/10.1016/j.fct.2005.09.001

21. Bagg J, Jackson MS, Petrina Sweeney M, Ramage G, Davies AN. Susceptibility to Melaleuca alternifolia (tea tree) oil of yeasts isolated from the mouths of patients with advanced cancer. Oral Oncol. 2006 May;42(5):487-92. https://doi.org/10.1016/i.oraloncology.2005.10.002

22. Li WR, Li HL, Shi QS, Sun TL, Xie XB, Song B, et al. The dynamics and mechanism of the antimicrobial activity of tea tree oil against bacteria and fungi. Appl Microbiol Biotechnol. 2016 Oct;100(20):8865-75. https://doi.org/10.1007/s00253-016-7692-4

23. Mondello F, De Bernardis F, Girolamo A, Cassone A, Salvatore G. In vivo activity of terpinen-4-ol, the main bioactive component of Melaleuca alternifolia Cheel (tea tree) oil against azole-susceptible and -resistant human pathogenic Candida species. BMC Infect Dis. 2006 Nov;6(1):158-66. https://doi.org/10.1186/1471-2334-6-158

24. Jones DS, Bruschi ML, Freitas O, Gremião MP, Lara EH, Andrews GP. Rheological, mechanical and mucoadhesive properties of thermoresponsive, bioadhesive binary mixtures composed of poloxamer 407 and carbopol 974P designed as platforms for implantable drug delivery systems for use in the oral cavity. Int J Pharm. 2009 May;372(1-2):49-58. https://doi.org/10.1016/j.ijpharm.2009.01.006

25. Lyu X, Zhao C, Yan ZM, Hua H. Efficacy of nystatin for the treatment of oral candidiasis: a systematic review and meta-analysis. Drug Des Devel Ther. 2016 Mar;10:1161-71. https://doi.org/10.2147/DDDT.S100795

26. Maghu S, Desai VD, Sharma R. Comparison of efficacy of alternative medicine with allopathy in treatment of oral fungal infection. J Tradit Complement Med. 2015 Mar;6(1):62-5. https://doi.org/10.1016/i.jtcme.2014.11.023

27. Tonon CC, Francisconi RS, Bordini EA, Huacho PM, Sardi JC, Spolidorio DM. Interactions between Terpinen-4-ol and Nystatin on biofilm of Candida albicans and Candida tropicalis. Braz Dent J. 2018 Jul-Aug;29(4):359-67. https://doi.org/10.1590/0103-6440201802073

28. Sudjana AN, Carson CF, Carson KC, Riley TV, Hammer KA. Candida albicans adhesion to human epithelial cells and polystyrene and formation of biofilm is reduced by sub-inhibitory Melaleuca alternifolia (tea tree) essential oil. Med Mycol. 2012 Nov;50(8):863-70. https://doi.org/10.3109/13693786.2012.683540

29. Comin VM, Lopes LQ, Quatrin PM, Souza ME, Bonez PC, Pintos FG, et al. Influence of Melaleuca alternifolia oil nanoparticles on aspects of Pseudomonas aeruginosa biofilm. Microb Pathog. 2016 Apr;93:120-5. https://doi.org/10.1016/j.micpath.2016.01.019

30. Souza ME, Lopes LQ, Bonez PC, Gündel A, Martinez DS, Sagrillo MR, et al. Melaleuca alternifolia nanoparticles against Candida species biofilms. Microb Pathog. 2017 Mar;104:125-32. https://doi.org/10.1016/i.micpath.2017.01.023

31. Mah TF, O'Toole GA. Mechanisms of biofilm resistance to antimicrobial agents. Trends Microbiol. 2001 Jan;9(1):34-9. https://doi.org/10.1016/S0966-842X(00)01913-2

32. Dumitru R, Hornby JM, Nickerson KW. Defined anaerobic growth medium for studying Candida albicans basic biology and resistance to eight antifungal drugs. Antimicrob Agents Chemother. 2004 Jul;48(7):2350-4. https://doi.org/10.1128/AAC.48.7.2350-2354.2004

33. Li Z, Sun J, Lan J, Qi Q. Effect of a denture base acrylic resin containing silver nanoparticles on Candida albicans adhesion and biofilm formation. Gerodontology. 2016 Jun;33(2):209-16. https://doi.org/10.1111/ger.12142

34. Nogueira JH, Gonçalez E, Galleti SR, Facanali R, Marques MO, Felício JD. Ageratum conyzoides essential oil as aflatoxin suppressor of Aspergillus flavus. Int J Food Microbiol. 2010 Jan;137(1):55-60. https://doi.org/10.1016/i.ijfoodmicro.2009.10.017 